\title{
The problem of satisfaction conditions and the dispensability of $i$-desire
}

This is a penultimate version. The final version will be available at Springer via http://dx.doi.org/10.1007/s10670-015-9731-4; citations should be to the final version.

\begin{abstract}
The problem of satisfaction conditions arises from the apparent difficulties of explaining the nature of the mental states involved in our emotional responses to tragic fictions. Greg Currie has recently proposed to solve the problem by arguing for the recognition of a class of imaginative counterparts of desires - what he and others call i-desires. In this paper I will articulate and rebut Currie's argument in favour of i-desires and I will put forward a new solution in terms of genuine desires. To this aim I will show that the same sort of puzzling phenomenon involved in our responses to tragic fictions arises also in a non-fictional case, and I will offer a solution to the problem of satisfaction conditions that dispenses with i-desires. The key to the explanation is in the notion of condition-dependent desires triggered by fictions.
\end{abstract}

Keywords: desire; i-desire; fiction; tragedy; imagination; Currie; Doggett \& Egan

\section{Introduction}

Over the past two decades philosophers and cognitive scientists have been increasingly interested in issues related to the distinction between genuine desire and a hypothetical imaginative counterpart of desire - or $i$ desire. It is a widely accepted view that certain states of mind involved in episodes of imagination are significantly like states of belief and that what distinguishes genuine beliefs from belief-like imaginings is the functional role they play in cognition'. That is, beliefs and belief-like imaginings have different causal interactions with stimuli, behaviours and other mental states. Proponents of i-desires suggest that just as there are imaginative counterparts of beliefs there are also imaginative counterparts of desires, which are easily confused with desires but are not really desires. Rather, they are a special kind of imagining that has gone unrecognized.

One influential argument in favour of the introduction of i-desires comes from considerations about our imaginative engagement with fictions ${ }^{\mathrm{ii}}$. Originally Currie (1997) introduces i-desires to account for our 
emotional responses to the fates of fictional characters and events that do not exist. He suggests that just like our emotional responses to the fates of real people and events are generated by the combination of real beliefs and desires, our emotional responses to the fates of fictional individuals and events are generated by the combination of belief-like imaginings and i-desires. A similar argument appears in Currie \& Ravenscroft $(2002,20)$, where they claim that just like emotions generated from beliefs must implicate desires, emotions generated from belief-like imaginings must implicate i-desires. However, this is contentious because contemporary studies on emotional responses do not establish that emotions necessarily implicate desires. Standard explanations appeal to processes of appraisal drawing upon a subject's available information about the situation, independently of whether this is fact or fiction iii. So, Doggett \& Egan $(2012,277)$ suggest that at least some emotional responses implicate desires, and that emotional responses generated within imaginative contexts implicate i-desires.

Proponents of i-desires argue that when we imaginatively engage with works of fiction we have desires that are difficult to explain according to our traditional understanding of what a desire is. They make three different arguments to support this claim. First, when we imaginatively engage with works of fiction we have desires that violate the normative constraints governing genuine desires. Currie claims that "Desires can be shown to be unreasonable, or at least unjustified, if they fail to connect in various ways with the facts" (2002, 211). I feel upset when Othello kills Desdemona. My reaction makes it tempting to say that I do not want Desdemona to die. Yet, the reasonableness of my wanting that she not die is not undercut by the fact that I know that there is no such person as Desdemona. So, the apparent desire for Desdemona's wellbeing must really be an $i$-desire. Similarly, Doggett \& Egan claim that since we know that the fictional individuals described in stories do not exist, it would be irrational to have any desires about them. As they write: "you know that your desire is directed at someone you know does not, maybe could not, exist. That is part of what makes the desire irrational" $(2012,286)$. So, again, the relevant mental states must be i-desires.

Against Currie's argument, Kind $(2011,425)$ points out that we do have genuine desires about things and situations that we know not to exist, e.g. past, future and counterfactual things and situations. I may desire to meet my great-great-grandmother; I may desire to meet my great-great-grandchildren; and I may desire to have a brother. These desires are so prosaic that it is very hard to raise any special puzzle about them. As a consequence, it seems difficult to raise any special puzzle regarding my desires about Desdemona. A similar 
3 | The dispensability of i-desire

reply would apply to Doggett \& Egan's claim. A sterile woman wanting to conceive and give birth to a child she knows she cannot have is hardly described as not having a genuine desire, irrespectively of whether one should judge such a desire as rational or irrational.

The second argument made in favour of i-desires is that in imaginative contexts these mental states do not motivate action in the way in which desires normally do. Currie notices that "....if imagining led me to have desires appropriate to a merely imagined situation, I might end up acting in dangerous ways" (2002, 211). The standard theory of desires in contemporary philosophy of mind is motivational. Roughly stated, to desire that $p$ is a matter of being disposed to act in ways that would tend to bring it about that $p$ in a world in which one's beliefs were true (Stalnaker 1984, 15). But my desire that Desdemona not die does not prompt me to try to save her. Given the standard motivational picture, and assuming that I have a genuine desire for her safety, my inaction is puzzling.

In response to a similar argument presented by Currie \& Ravenscroft $(2002,20)$, Carruthers (2003) suggests that "real desires will normally lead to real actions only when interacting with real beliefs". I do not try to save Desdemona because I merely imagine that what happens on stage happens for real. Furthermore, Kind (2011, 426-7) points out that some desires do not necessarily motivate us to bring the desired end about. An ancient Greek mathematician desiring that $\pi$ not be expressible as a fraction of two natural numbers can do nothing to affect the value of $\pi$ (Schroeder 2004,16$)$. And someone wanting that a certain plane departed on time can do nothing to change the past and make the plane depart on time (Mele 1995, 394). My inability to change a situation does not deter me from forming genuine desires about it. Similarly, my inability to control the unfolding of fictional events does not deter me from having genuine desires about them.

Doggett \& Egan $(2007,13-14 ; 2012,283-285)$ make a third argument in favour of i-desires by claiming that there is no adequate way to understand the contents of these mental states if they are genuine desires. Consider my desire that Tony Soprano, the fictional Mafia boss from the TV series The Sopranos, be safe from the police. Doggett \& Egan individuate and reject three possible interpretations of its content. First, this could not be a desire that anybody fitting Tony's description be safe from the police because I would want any such person to be in jail. Second, it could not be a desire that, according to the fiction, Tony be safe from the police because this would be a desire about the story. I might have no such desire (suppose I trust the authors and think that whatever they decide will be best for the story), or I might have a contrary desire that, 
4 | The dispensability of i-desire

according to the fiction, Tony not be safe (suppose I think that this would make for a better story). Third, this could not be a desire that the fictional character Tony Soprano be safe from the police because the content of the fiction determines whether a fictional character has certain properties, and this would rationally require that one has the corresponding desire about the fiction. This, Doggett \& Egan argue, would entail that I have an irrational response to the story. I would have a desire that according to the fiction Tony be safe, and a desire that according to the fiction Tony not be safe.

In response to the latter consideration Kind $(2011,429)$ notices that contradictory desires are commonplace and do not characterize our imaginative engagement with fiction in any special way. A mother whose only child is a high school senior might want him to go away to university because that would be the best choice for his own good. At the same time, she might want him to stay home and attend a local institution because she is afraid of having an empty nest. One might wonder about how a theory of rationality should deal with this sort of cases, but such a theory is out of the scope of the present work.

Doggett \& Egan's problem of content relates to a new and particularly cunning argument made in favour of idesires. Currie (2010) contends that if certain mental states triggered by tragic fictions are really desires then there is no adequate way to understand their satisfaction conditions. This is the argument I am going to consider at some length in this paper.

\section{The problem of satisfaction conditions}

Currie notices that our responses to tragic fictions are characterized by the combination of two apparently contradictory mental states. We would be disappointed if a theatre director of Shakespeare's Othello had Desdemona alive at the end of the play. That would seem dramatically wrong and would clearly go against the author's original intentions. Yet, we are also upset by her death. Currie initially characterizes the two states respectively as:

1. We want the fiction to be such that something, $E$, occurs in it;

2. We react in ways that make it tempting to say that we want $E$ not to occur.

He calls the combination of (1) and (2) a tragic response, and the fiction to which it is a response tragic or a tragedy. Currie's problem consists in asking whether (2), which is the tempting thing to say, is also the right thing to say. Answering this question means choosing one of three candidate solutions. 
5 | The dispensability of i-desire

According to the simple solution ${ }^{\text {iv }}$ the intuitive assessment of the situation is right, since the mental state in

(2) is desire and its object is the event that Desdemona not die, without any reference to the fiction:

3. We desire that $E$ not occur.

By combining (1) and (3) we have that we desire that Othello be a play wherein Desdemona dies and further desire that Desdemona not die.

According to the change-of-content solution ${ }^{\vee}$, the intuitive assessment of the situation is wrong, since the relevant mental state in (2) is desire, but the object of the desire is not the event narrated in the fiction, but rather the fiction itself:

4. We desire the fiction to be such that $E$ not occur in it.

By combining (1) and (4) we have that we desire Othello to be a play wherein Desdemona dies and also desire it to be a play wherein she does not die.

According to the change-of-attitude solution ${ }^{\mathrm{vi}}$ the intuitive assessment of the situation is wrong, since the object of the mental state is the event itself while the attitude is an imaginative counterpart of desire:

\section{We $i$-desire that $E$ not occur.}

By combining (1) and (5) we have that we desire Othello to be a play wherein Desdemona dies and $i$-desire that she not die.

My main aim in this paper is to critically assess Currie's argument in favour of the change-of-attitude solution and to spell out a new explanation coherent with the simple solution. In what follows I will articulate Currie's argument (Section 4), I will cast some doubts on its plausibility by showing that a similar argument can be made in a non-fictional case (Section 5), and I will provide a solution to the problem of satisfaction conditions that dispenses with i-desires (Section 6). The underlying strategy will be to show that the problem of satisfaction conditions arises from an overly restrictive notion of desire. The key to the explanation is in the notion of condition-dependent desires triggered by fictions. Since the notion of condition-dependent desires has been introduced by Currie himself, this is a move to which he could not object. But first I will briefly explain why we should put aside the change-of-content solution as a nonstarter. 


\section{What is wrong with the change-of-content solution}

The change-of-content solution offers a straightforward explanation of the typical tension we experience with tragedies as the result of the combination of (1) and (4) as two genuinely contradictory desires. In Nichols's own words: "The tension we experience in watching Othello arises because we have conflicting real desires about the play. One desire is that the fiction have it that Desdemona be saved; the other desire is that the play be tragic" $(2004,333)$.

Currie $(2010,636)$ notices that the change-of-content solution postulates an ambiguity in people's responses to tragic fictions that they do not have. Most people who want to see a tragic fiction have no ambivalence about what shape they want for Othello's ending. Hence, their responses would not be properly accounted for by saying that they want Othello to be such that Desdemona dies and that they want Othello to be such that Desdemona not die. And talking about our emotional responses to Romeo and Juliet, Doggett \& Egan object: "If you were so conflicted, the fiction would disappoint you by not giving you everything you want. But Romeo and Juliet was not disappointing for us in this way" (2012, 281-282). Instead, we are aesthetically pleased by the tragedy and distinctively saddened by the death of the two young characters.

This relates to a more serious problem for the change-of-content solution that comes from worries about what really concerns us when we imaginatively engage with fictions ${ }^{\text {vii }}$. When I watch Othello I may have two different concerns. The first involves what one may call an external or descriptive perspective: considering the play I desire it to be such that Desdemona dies. This corresponds to schema (1). The second concern involves what one may call an internal or participatory perspective: considering the events that I experience as a spectator, I react in ways, which make it tempting to say that I desire that Desdemona not die. This corresponds to schema (2). In this case the subject matter of my concern is Desdemona's death, not the play. So, while (1) is a schema for a genuine desire about the fiction, (2) is a schema for a desire about the fictional events described in the play. The change-of-content solution does not distinguish between the different objects of my mental states and wrongly interprets (1) and (2) in the same way, as desires about the fiction. While the external perspective is appropriate for the interpretation of mental states corresponding to schema (1), it is certainly not appropriate for the interpretation of mental states corresponding to schema (2). Thus, the change-of-content solution is a nonstarter. 


\section{Currie's argument}

In his attempt to motivate the change-of-attitude solution Currie builds a case that is supposed to work as a counterexample to the simple solution. To avoid possible complications with the metaphysics of fictional characters he imagines a story wherein the fictional character in question is real and about whom the viewer has real desires.

Suppose I am watching a drama called Death of a Prime Minister, which imagines the murder of Margaret Thatcher and its political repercussions. Currie stipulates that, watching the drama: i) I desire that, in the play, Mrs Thatcher die; and, as a matter of fact, ii) I want Mrs Thatcher to have a long and happy life. (i) and (ii) are instances of schemas (1) and (3) respectively, the combination of which corresponds to the interpretation of an audience's tragic response according to the simple solution. Currie's objection is that the simple solution cannot account for my tragic response to the drama. Given (i) and (ii), Death of a PM should elicit a tragic response. Yet, he claims, it does not, because agreeing to (i) and (ii) "leaves it entirely open how I respond to the fiction" $(2010,634)$. Although I am, by stipulation, a true admirer of Mrs Thatcher, I may be on the side of the assassin if the authors were so good to describe him in ways that change my perspective. In this case, I might have a third desire: iii) I desire that Mrs Thatcher die. The combination of (i) and (iii) is not a tragic response coherent with the simple solution, because (i) corresponds to (1) but (iii) does not correspond to (3).

Upholders of the simple solution could modify their proposal by claiming that a drama is tragic for me if I have desires of kind (1) and (3) and furthermore neither desire is dominated by more salient contrary desires. The stipulated desire for the wellbeing of Mrs Thatcher is a stable, background desire of mine. But when watching the drama an occasional and unstable desire that she die might be triggered. According to Currie, this would be a condition-dependent desire, one that is triggered by the drama and dominates my thinking for its entire duration. But he furthermore claims that this is not what happens with Death of a PM. The long-term desire that Mrs Thatcher not die, i.e. (ii), is satisfied if she does not die. The conditiondependent desire that she die, i.e. (iii), is satisfied if she is killed. Yet, if she came into the room pursued by an assassin, my condition-dependent desire that she be killed would be satisfied not by what happens to her when she enters the room but by what happens to her in the fiction. So, the satisfaction conditions of (iii) 
8 | The dispensability of i-desire

would not be simply that Mrs Thatcher die but rather that she die according to the fiction. And this corresponds to schema (1), which is a desire about the fiction.

At this point, from the exclusion of the relevant alternatives, Currie proposes a test (SC) to distinguish desires from i-desires:

(SC): A putative desire $A$ is an i-desire and not really a desire if $A$ has satisfaction conditions, a canonical statement of which makes reference to a fiction which is not also the object of $A$.

By (SC) we must conclude that (iii), the desire that Mrs Thatcher die, which has been hypothetically prompted by the fiction, is not really a desire but an i-desire. And so the change-of-attitude theory is right while the simple theory is wrong.

Currie recognizes that (SC) might be puzzling: "Why say there are these peculiar i-desires, with odd satisfaction conditions, given by (SC), which don't match their contents?" $(2010,635)$. On the assumption that the satisfaction conditions of a desire and its (externally individuated) content are the same there should be no discrepancy here. Yet, (SC) postulates that the satisfaction conditions of an i-desire include reference to a fiction, but its content does not include the fiction as its object. Otherwise, to i-desire that Mrs Thatcher not die would be really to desire something about Death of a PM. And this would be a disguised version of the change-of-content solution that we rejected at the beginning as a non-starter. Currie avoids falling into contradiction by building on the analogy with belief-like imagining. More specifically, he distinguishes between the satisfaction conditions and the contents of i-desires by drawing on an analogous distinction between correctness conditions and contents for belief-like imaginings.

We would be wrong in imagining that Bill Sykes is a kind person because that is not how things are represented in Oliver Twist. The correct imagining would be that he is a violent criminal because this is how things are represented in the story. However, the proposition that Bill Sykes is a violent criminal is not really true, it is only true according to the fiction. On the other hand, the proposition that according to the fiction Sykes is a violent criminal is straightforwardly true and appropriate for me to believe. So, the same state of affairs, i.e. that according to the fiction Sykes is a violent criminal, makes it appropriate for me to imagine that Sykes is a violent criminal and to believe that according to the fiction he is a violent criminal. By analogy, we can i-desire that Sykes is kind and we can also genuinely desire that according to the fiction he is kind. The 
9 | The dispensability of i-desire

two mental states have distinct contents, but what would satisfy them is the same state of affairs, i.e. that according to the fiction Sykes is kind.

\section{The lab experiment}

In this section and in the next one I will argue that the i-desire solution to the problem of satisfaction conditions is based on an overly restrictive notion of desire. Here I will show that the very same combination of mental states characterising our responses to tragic fictions also characterises our responses to nonfictional cases. In the next section I will articulate a solution in terms of genuine desires.

Suppose that I attend for the first time a training session on the impact of stress on decision-making in a laboratory for behavioural neuroscience. The experiment includes brain surgery on subjects, usually rats, which eventually causes their death. When I attend the experiment I have the following desire: iv) I want the experiment to be such that the rat dies (suppose that is the only way to gather the necessary data). Yet, I am also perturbed by the death of the rat. In other words, I react in ways that make it tempting to say that I have another desire: v) I want that the rat not die. These apparently contradictory mental states, (iv) and (v), can be represented respectively as:

6. I want the experiment to be such that something, $E$, occurs in it;

7. I react in ways that make it tempting to say that I want $E$ not to occur.

Schema (6) clearly corresponds to our original schema (1) - with the appropriate substitution of reference to the fiction with reference to the lab experiment - and schema (7) corresponds to schema (2). Hence, I will call the combination of (6) and (7) a tragic* response to the lab experiment. Now we can run a new version of Currie's argument starting by asking whether (7) is really the right thing to say.

According to the simple* solution, our initial intuition is correct, since the mental state in (7) is desire and its object is the event that the rat not die, without any reference to the experiment:

8. I desire that $E$ not occur.

Given the combination of (6) and (8), I want the experiment to be such that the rat dies and I genuinely want that the rat not die. There is a certain tension between (6) and (8), but there is no genuine contradiction because they are about different objects, i.e. the lab experiment and a certain event. 
According to the change-of-attitude* solution, (7) would be a new kind of desire-like state, say an $x$-desire, which seems to be a genuine desire but is really a different kind of mental state. Thus, (7) can be represented as:

\section{I $x$-desire that $E$ not occur.}

Given the combination of (6) and (9), I want the experiment to be such that the rat dies and I $x$-desire that the rat not die.

According to Currie, the problem with the simple interpretation of my tragic response to Death of a $P M$ is that the combination of (i) and (ii) - corresponding to (1) and (3) - leave it open how I respond to the drama. But the very same consideration can be made about the description of my reaction to the performance of the lab experiment. The combination of (iv) and (v) - corresponding to (6) and (8) - leaves it completely open how I react to the experiment. Although I am, as a matter of fact, very sensitive to the wellbeing of animals, I might so much value the lab assistant's technical skills that when I attend the experiment I have a different kind of desire - say (vi) - that the rat die. So, my response to the lab experiment would not be tragic*.

Now suppose that we slightly modify the proposal and claim that the lab experiment is tragic ${ }^{\star}$ for me if I have desires of type (6) and (8) and furthermore neither desire is dominated by more salient contrary desires. The desire for the wellbeing of the rat, i.e. (v), is a stable background desire of mine. However, when I attend the experiment, an occasional and unstable desire that the rat die, i.e. (vi), is triggered. According to Currie's reasoning, this would be a condition-dependent desire triggered by the experiment. Furthermore, $(v)$, the long-term desire that the rat not die, is satisfied if it does not die; and (vi), the condition-dependent desire that the rat die, is satisfied if it is killed. Yet, if the rat somehow managed to escape from its cage and was pursued by someone trying to kill it, my condition-dependent desire that it die would be satisfied not by what happens to the rat when escaping its cage, but by what happens to the rat in the experiment. So, the satisfaction conditions of the condition-dependent desire prompted by the experiment would not be simply that the rat die, it would be that it dies in the experiment. And this corresponds to schema (6), which is a desire about the experiment.

At this point, from the exclusion of the relevant alternatives, a test similar to (SC) can be offered to distinguish a novel desire-like state from genuine desires: 
$\left(\mathrm{SC}^{*}\right)$ : A putative desire $B$ is an $x$-desire and not really a desire if $B$ has satisfaction conditions, a canonical statement of which makes reference to a lab experiment which is not also the object of $B$.

The same discrepancy between satisfaction-conditions and contents originally found in the fictional case has been found in this non-fictional case. By $\left(\mathrm{SC}^{*}\right)$ we must conclude that (vi), the apparent desire that the rat die, which has been hypothetically prompted by the experiment, is not really a desire but an $x$-desire. Yet, no one would introduce a new mental state to explain our reaction to the lab experiment or to any other cases that do not engage our imagination. So, why should we accept it in the fictional case?

One might argue that since the fictional nature of the original scenario is an essential factor that is missing from the real scenario desires and i-desires must have different structures. Desires tend to change the world, but since I already know that Death of a PM is a fiction, I do not desire to save Mrs Thatcher in the way in which I would desire to save her in a real situation. The fact that the original scenario is fictional makes it different from the lab experiment scenario. This objection relates to the problem of motivation I described in the Introduction: when we imaginatively engage with works of fiction we have desires that do not seem to motivate action in the way desires usually do. We can explain the typical inaction involved in our imaginative engagement with fiction by arguing that desires motivate action only in combination with real beliefs (Carruthers 2003). And we can point out that desires generated within a fictional scenario are motivationally inert just as many desires we have in real scenarios (Kind 2011). The upshot is that the fictional nature of the original scenario is not essential to the distinction between i-desires and genuine desires.

Still, one might try to argue that since we already recognize belief-like imaginings there is motivation to recognize i-desires in a way that there is not to recognize other sorts of desire-like states. But this is exactly what is at stake in the original argument leading to the formulation of (SC). Blocking the iteration of the argument in different contexts - hence the move from (SC) to $\left(\mathrm{SC}^{*}\right)$ - on the basis of the fact that one is only interested in presupposing the analogy between belief-like imaginings and i-desires would be strikingly ad hoc. The postulation of i-desires can only be motivated by theoretical considerations about the explanatory sufficiency of a theory that dispenses with them. Currie's argument is supposed to provide that kind of genuine and plausible motivation based on the insufficient explanatory power of the simple solution. So, we need to show that there is an alternative explanation of our responses to the fictional case in terms of genuine desires. In the next section I will develop a solution to the problem of satisfaction conditions in the 
non-fictional case, and I will then extend it to the fictional case.

\section{The right version of the simple solution}

When discussing the possible modification of the simple solution Currie claims that condition-dependent desires are different from conditional desires. The difference lies in the fact that conditional desires have satisfaction conditions of the form 'if $p$ then $q$ ', while condition-dependent desires have simply the form ' $q$ ':

A person whose long term background desire is to stay sober may, when confronted with temptation, acquire the desire to drink. This is a condition-dependent desire, and not a conditional desire; it is not the desire to drink if confronted by certain things, but the desire simply to drink: a desire the subject has just when so confronted. $(2010,634)$

Let us assume Currie's distinction between conditional desires and condition-dependent desires and let us focus on the latter.

The notion of a condition-dependent desire can be articulated in ordinary terms by appealing to the distinction between intrinsic desires and instrumental desires. We have an intrinsic desire when we want a certain state of affairs for itself, e.g. wanting pleasure for its own sake, wanting the wellbeing of the people one loves, and more. To desire something intrinsically is compatible with desiring it also for some other ends. For example, my desire that my mother be healthy can be partially instrumental since this would be a means for me not to worry about her wellbeing. We have an instrumental desire when we want a certain state of affairs merely as a means to some other ends, e.g. wanting to undergo a dental surgery as a means to relieving toothache. Most condition-dependent desires are straightforward examples of intrinsic desires. My condition-dependent desire to drink is a desire I have for its own sake, which can be partially instrumental if drinking is also a means to be relieved of thirst.

However, not all condition-dependent desires are intrinsic. The lab experiment triggers an occasional and unstable desire that the rat die, i.e. (vi), which is a condition-dependent desire in that its very existence is conditional on the performance of the experiment. Furthermore, (vi) prevails over (v), which is my stable and long-term desire that the rat not die, because I have a strong desire to learn the relevant experimental technique from a highly skilled experimenter. Thus, while (v) is an intrinsic desire for the wellbeing of the rat, (vi) is merely instrumental. I do not want that the rat die for the sake of it, I want that it die as a means for me 
to learn the experimental technique. This case is exactly paralleled by my response to Death of a $P M$. My occasional and unstable desire that Mrs Thatcher die, i.e. (iii), which contradicts my long term and stable desire for her wellbeing, i.e. (ii), is a condition-dependent desire triggered by the drama. Its very existence is conditional on the performance of the drama. Just like (vi), (iii) is not an intrinsic desire: I do not want that Mrs Thatcher die for the sake of it. I want that she die as a means for the assassin to show off his Jackal-like professional skills. If, on the other hand, Mrs Thatcher entered the room pursued by an assassin (iii) would be probably shut down.

Now suppose that, unsuspected by me, everything happening on stage is true, the actors are Margaret Thatcher and a real assassin, and Mrs Thatcher is really murdered (not just stage murdered). Since I do not realize that what happens on stage happens for real, my reaction to the play will be the one I have just described. Belief-like imagining is the attitude I assume towards the events happening on stage. A conditiondependent desire that Mrs Thatcher die is elicited, and this is satisfied only within the fiction, i.e. within the imaginative context created by the play. If I were to believe that Thatcher is really murdered I would probably not have any desire for her death. The imaginative context of the play allows some overall desires - such as the intrinsic desire for highly skilled individuals to succeed - to come to the emotional forefront while other desires - such as the intrinsic desire for the wellbeing of Mrs Thatcher - recede to the background in their impact on emotional responses.

We only need to develop a bit Currie's alleged counterexample to see that his notion of a tragic response to fiction can be easily accounted for by a slightly modified version of the simple solution. Currie postulates that when I watch Death of a PM I have two apparently contradictory mental states, i.e. (i), which is a desire elicited by the fiction and about the fiction, and (ii), which is a long-term desire about Mrs Thatcher's wellbeing not elicited by the fiction. Why, given the simple solution, does Death of a PM not elicit a tragic response from me? By postulation, (ii) is the desire that Mrs Thatcher not die; and by the very same postulation, (ii) is also a stable, long-term desire not elicited from me by the fiction. The case is built in such a way that while (i) is certainly elicited by the fiction, (ii) is not; and so the combination of (i) and (ii) is not elicited by the fiction, only (i) is. This is the reason why, given (i) and (ii), it is still open how I react to the drama. It is a consequence of the way in which Currie constructs the case that any other desire, including (iii), can be prompted by the fiction. 
So, in order for me to have a tragic response to the drama I should have a condition-dependent desire, elicited by the fiction, that Mrs Thatcher not die. Call this (ii*). Desires (ii) and (ii*) are both intrinsic and they have the same content. But while the satisfaction condition of (ii) is merely that Mrs Thatcher not die, the satisfaction conditions of (ii*) include reference to the drama without this being also its object. Indeed, if we have $\left(i^{*}\right)$, it does not follow that the simple solution is wrong. It only follows that we can have a genuine (although occasional) desire prompted by the drama that Mrs Thatcher not die, one that can be only satisfied in the drama. When watching Death of a PM I desire it to be a play wherein Mrs Thatcher dies, but I also desire that she not die in the drama. In this way Death of a PM can certainly elicit a tragic response from me without any appeal to $i$-desires.

\section{Conclusions}

I argued that the same sort of responses characterising our tragic response to fiction characterise also our responses to a non-fictional case. The same discrepancy between satisfaction conditions and contents characterising desires elicited by fiction characterises also desires elicited by non-fictional triggers. Currie's argument is based on the purported insufficient explanatory power of a theory that deploys only genuine desires. However, once we develop a solution for the non-fictional case in terms of genuine desires it seems only natural to extend the same solution to the fictional case. This is what I did in the above section, where I showed that the key to the explanation of our tragic responses to fictions is in the correct characterisation of condition-dependent desires triggered by fictions.

It is worth pointing out that thanks to Currie's distinction between content and satisfaction conditions we now have a solution to Doggett \& Egan's (2012) problem of content. My desire that Tony Soprano be safe from the police is a condition-dependent desire that Tony be safe. This is a desire elicited by the fiction from an internal perspective, i.e. within an imaginative context where desires combine with belief-like imaginings. And since we can have desires about things that we know not to exist (as pointed out by Kind 2011) we can also have desires about Tony Soprano, the non-existent Mafia Boss. However, this desire can only be satisfied within the fiction. In this way the right version of the simple solution offers also a straightforward explanation of the typical tension we experience with tragedies. The tension between our desire that The Sopranos be such that Tony is not safe and our desire that Tony be safe arises because we have desires with different contents but contradictory satisfaction conditions. The desire that The Sopranos be such that Tony is not 
safe can be satisfied only if according to The Sopranos Tony is not safe. The desire that Tony be safe can be satisfied only if according to The Sopranos Tony is safe. Clearly, the two conditions cannot be met at the same time.

I conclude by claiming that there is no special class of mental states prompted by fictions that can be identified with $i$-desires. At most, there are desires with satisfaction conditions a canonical statement of which includes reference to a fiction that is not also their object. These satisfaction conditions pertain to condition-dependent desires elicited by fiction, but they do not individuate any novel mental states. All the explanatory work needed to solve Currie's problem of satisfaction conditions can be done in terms of genuine desires. The notion of $\mathrm{i}$-desire is not needed.

\section{References}

Carruthers, P. (2003). Review of 'Currie and Ravenscroft. Recreative Minds'. Notre Dame Philosophical Reviews

Carruthers, P. (2006). Why Pretend. (In S. Nichols (Ed.), The Architecture of the Imagination (pp. 89-109). Oxford: Oxford University Press)

Currie, G. (1995). The moral psychology of fiction. Australasian Journal of Philosophy, 73(2), 250-259

Currie, G. (1997). The Paradox of Caring: Fiction and the Philosophy of Mind. (In M. Hjort and S. Laver (Eds.) Emotion and the Arts (pp. 63-77). Oxford: Oxford University Press)

Currie, G. (1998). Pretence, Pretending, and Metarepresenting. Mind and Language, 13(1): 35-55.

Currie, G. (2002). Desire in Imagination. (In T. S. Gendler and J. Hawthorne (Eds.) Conceivability and Possibility (pp. 201-21). Oxford: Oxford University Press)

Currie, G. (2010). Tragedy. Analysis, 70, 632-638

Currie, G. \& Ravenscroft, I. (2002). Recreative Mind. (Oxford: Oxford University Press)

Doggett, T. \& Egan, A. (2007). Wanting Things You Don't Want: The Case for an Imaginative Analogue of Desire. Philosophers' Imprint, 7(9), 1-16

Doggett, T. \& Egan, A. (2012). How We Feel About Terrible, Non-Existent Mafiosi. Philosophy and Phenomenological Research, 84(2), 277-306

Gendler, T. S. (2008a). Alief and Belief. Journal of Philosophy, 105, 634-663 
Gendler, T.S. (2008b). Alief in Action (and Reaction). Mind and Language, 23, 552-585

Griffiths, P. (1997). What Emotions Really Are. (Chicago: University of Chicago Press)

Kind, A. (2011). The Puzzle of Imaginative Desire. Australasian Journal of Philosophy, 89, 421-439

Mele, A.R. (1995). Motivation: Essentially Motivation-Constituting Attitudes. The Philosophical Review, 104(3), 387-423

Nichols, S. (2006). Just the Imagination: Why Imagining Does not Behave Like Believing. Mind \& Language, 21(4), 459-474

Nichols, S. (2004a). Review of Recreative Minds. Mind 113, 329-34

Nichols, S. (2004b). Imagining and Believing. The Promise of a Single Code. The Journal of Aesthetics and Art Criticism 62(2), 129-139

Nichols, S. \& S. Stich (2000). A Cognitive Theory of Pretence. Cognition 74, 115-147

Nichols, S. \& S. Stich (2003). Mindreading. An Integrated Account of Pretence, Self-Awareness, and Understanding Other Minds. (New York: Oxford University Press)

Prinz, J. (2004). Gut Reactions. (New York: Oxford University Press)

Robinson, J. (2005). Deeper Than Reason. (New York: Oxford University Press)

Schroeder, T. (2004). Three Faces of Desire. (Oxford: Oxford University Press)

Stalnaker, R. (1984). Inquiry. (Cambridge, MA: MIT Press)

Walton, K. (1990). Mimesis as Make-Believe. (Cambridge University Press)

Walton, K. (1997). Spelunking, Simulation, and Slime: On Being Moved by Fiction. (In M. Hjort and S. Laver (Eds.) Emotion and the Arts (pp. 37-49). Oxford: Oxford University Press)

Weinberg, J.M. \& Meskin, A. (2005). Imagine that! (In M. Kieran (Ed.) Contemporary Debates in Aesthetics and the Philosophy of Art (pp. 222-35). Oxford: Blackwell)

Weinberg, J.M. \& Meskin (2006). Puzzling over the Imagination: Philosophical Problems, Architectural Solutions. (In S. Nichols (Ed.) The Architecture of the Imagination. New Essays on Pretence, Possibility, and Fiction (pp. 175-202). Oxford: Clarendon Press)

Yablo, S. (2001). Go figure: A path through fictionalism. Midwest Studies in Philosophy, 25, 72-102

\footnotetext{
'Paradigmatically, Weinberg \& Meskin remark that over the last two decades "two crucial insights have emerged from this research [in cognitive psychology and empirically oriented philosophy]: that there are significant functional similarities between imaginative states and belief states, but that distinct cognitive
} 
systems underwrite our imaginative and doxastic capacities" $(2006,178)$. For example, according to Nichols \& Stich's influential cognitive theory of pretence imagined representations (so the metaphor goes) are stored in a distinct Possible World Box: "Like the Belief Box and the Desire Box, the Possible World Box contains representation tokens. However, the functional role of these tokens - their pattern of interaction with other components of the mind - is quite different from the functional role of either beliefs or desires" $(2003,28)$. Nichols deploys the same idea when he explores the similarities and the discrepancies between imagination and belief (2004b, 2006). Inspired by Nichols \& Stich's boxology, Doggett \& Egan develop their own distinct theory of mind and assume that "mental states are represented by boxes and boxes are individuated by functional role" (2012, 279). Carruthers contends that "belief-like imaginings aren't real beliefs. They differ from real beliefs in crucial aspects of their functional role" $(2006,99)$. Currie remarks that defendants of simulation theories about knowledge of the mind of others "can certainly affirm that the internal functional roles of belief and pretence are similar, because the simulationist can say that pretence is off-line belief" $(1998,46, n .24)$. And Currie \& Ravenscroft develop this insight and explicitly appeal to "functional kinds" $(2002,17)$.

ii This is what Currie (1997) calls the paradox of caring and what Kind (2011) calls the problem of conative engagement with fictions.

iii Gendler (2008a, 2008b), Griffiths (1997), Prinz (2004), and Robinson (2005) present different arguments against the idea that emotional responses necessarily involve desires.

iv Upholders of the simple view are, e.g., Carruthers (2003, 2006), and Kind (2011).

${ }^{\vee}$ E.g., Nichols (2004) and Weinberg and Meskin (2005). According to Currie (2010, 633 footnote 2) Walton (1990, 258-59) can be also read as advocating a version of the change-of-content view.

${ }^{v i}$ Among the proponents of this view are Currie (1995, 2002, 2010); Currie and Ravenscroft (2002); and Doggett and Egan $(2007,2012)$. Walton (1997) seems to put forward a similar notion.

vii Yablo (2001) suggests a similar worry for the interpretation of sentences containing reference to numbers interpreted according to a fictionalist approach to mathematics. 